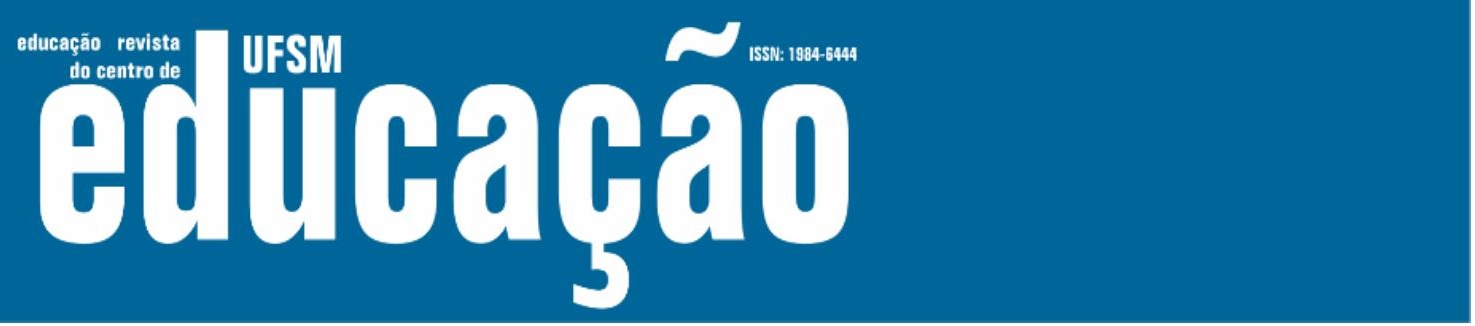

ISSN: 1984-6444 | http://dx.doi.org/10.5902/1984644460844

\title{
Mediações didáticas em uma aula de leitura na EJA - mulheres relendo suas realidades e o mundo
}

\author{
Teaching mediations in EJA reading classes - women rereading their \\ realities and the world
}

Marinaide Lima de Queiroz Freitas

Professora doutora na Universidade Federal de Alagoas, Maceió, Alagoas, Brasil. naide12@hotmail.com - http://orcid.org/0000-0003-3659-4165

Valéria Campos Campos Cavalcante

Professora doutora na Universidade Federal de Alagoas, Maceió, Alagoas, Brasil. vccavalcante1@hotmail.com - https://orcid.org/0000-0001-9512-1531

Recebido em 03 de outubro de 2020

Aprovado em 04 de novembro de 2020

Publicado em 30 de março de 2021

\section{RESUMO}

Este artigo apresenta uma reflexão sobre o ensino de Leitura da/na Educação de Jovens e Adultos (EJA), e traz como foco as mediações didáticas vivenciadas em uma aula de leitura. É recorte de uma pesquisa qualitativa, de base colaborativa (IBIAPINA, 2008), realizada em escolas públicas de Maceió, e desenvolvida no âmbito do Observatório Alagoano de Leitura na EJA (2011 a 2015), financiada pela Coordenação de Aperfeiçoamento de Pessoal de Nível Superior (Capes). No percurso, dialogavase sobre o ensino de Leitura e as didáticas/práticas desenvolvidas em sala de aula, perfil dos/as estudantes, suas histórias e necessidades de leituras, entendendo a leitura como prática social que acontece em todos os lugares: na vida, no trabalho e em diversas agências de letramento, incluindo nesse contexto a escola. Neste recorte, os resultados demonstraram que a sala de aula configurou-se como um espaço de exercício de autonomia, dos estudantes e da professora, quando puderam apropriarse da realidade, captar as pressões, alterando-as, transformando-as em invenções cotidianas, inéditas e irrepetíveis.

Palavras-chave: Leitura; Mulheres da EJA; Mediações didáticas.

\section{ABSTRACT}

This paper presents to the reader a reflection on the Reading teaching in EJA, that focuses on the didactic mediations experienced in a reading class. This research is part of a qualitative, collaborative-based research (IBIAPINA, 2008), carried out in public schools of Maceió, and developed as part of Observatório Alagoano de Leitura em EJA (2011 to 2015) project, financed by the Coordination for the Improvement of Higher Education Personnel (Capes). Along the way, dialogues about the teaching of 


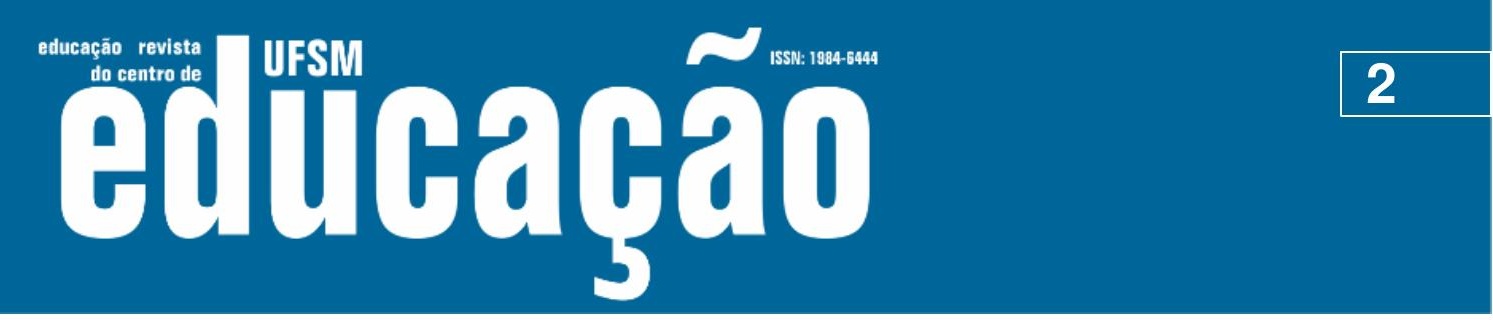

ISSN: 1984-6444 | http://dx.doi.org/10.5902/1984644460844

Reading and didactics/practices developed in the classroom were provided, considering the profile of the students, their stories and reading needs, and understanding reading as a social practice that happens everywhere: in life, at work and in various literacy agencies, including the school. Further in this article, the results showed that the classroom was set as a space for the exercise of students and the teacher autonomy, especially when they were able to appropriate the reality, capturing the pressures, changing them, and transforming them into unprecedented and unrepeatable everyday inventions.

Keywords: Reading; Women in EJA; Didactic mediations.

\section{Primeiras palavras}

Este artigo é um recorte da pesquisa denominada: A leitura e a formação de leitores, no estado de alagoas: estudo e intervenção de alfabetização, realizada pelo Observatório Alagoano de Leitura em Educação de Jovens e Adultos ${ }^{1}$, situada nas ações do Núcleo de Estudo, Pesquisa e Extensão sobre Alfabetização (Nepeal), pertencente ao Centro de Educação (Cedu), da Universidade Federal de Alagoas (Ufal). A investigação do referido Observatório envolveu quatro escolas públicas, que atuam com a Educação de Jovens e Adultos, situadas na periferia urbana de Maceió, sendo duas municipais e duas estaduais. Essas escolas concordaram com a pesquisa, por livre e espontânea vontade, com o desejo de transformar o ambiente de ensino, uma vez que se tratava de um processo de pesquisa-formação ${ }^{2}, \mathrm{com}$ abordagem colaborativo-interventiva (IBIAPINA, 2008), refletindo sobre mediações didáticas voltadas para área de leitura e a formação de leitores na EJA.

Buscou-se, no processo de estudo com os professores que durou quatro anos, a concepção de investigar com a escola e não sobre ela, contribuindo para que os integrantes da comunidade escolar se reconhecessem como produtores de conhecimentos. Nesse processo, há que se ressaltar a importância da mediação didática das professoras no ensino de leitura. Falar em mediação didática é falar sobre a presença do "outro" e da dinamicidade do signo. É falar da tensão, a reversibilidade, da impregnação da "palavra" que na [...] experiência verbal individual emerge e se configura em meio à incessante interação da enunciação dos outros, 


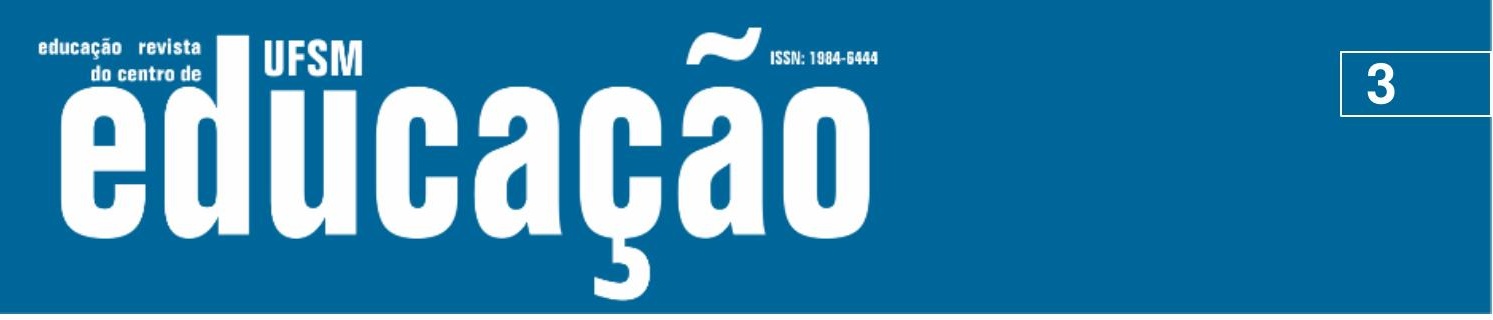

ISSN: 1984-6444 | http://dx.doi.org/10.5902/1984644460844

num processo, ao mesmo tempo, de incorporação/reação à palavra de outrem. (SMOLKA, 1991, p. 17).

Especificamente na EJA, as mediações didáticas devem ser comprometidas com uma postura perante o mundo, uma práxis política (FREIRE, 1996), que estabeleçam diálogos com as realidades e saberes dos educandos, os vínculos necessários para uma educação dialógica, problematizadora/emancipatória.

Ressalta-se, ainda, que no processo de aquisição de leitura na escola, sobretudo na EJA, a medição do professor é fundamental, pois "quanto mais conhecimento textual o leitor tiver, quanto maior a sua exposição a todo tipo de texto, mais fácil será sua compreensão" (KLEIMAN, 2004).

Leitura entendida como "uma atividade na qual leva-se em conta as experiências e os conhecimentos do leitor" (KOCH; ELIAS, 2009, p.11), compreendendo que "[...] a leitura de um texto exige [...] bem mais que o conhecimento do código linguístico [...]" (KOCH; ELIAS, 2009, p.11).

Nesse sentido, explicita-se que o/a leitor/a interage com 0 texto (re)significando-o, uma vez que o texto não está pronto, necessitando do/a leitor/a para atribuir sentido, considerando que a leitura é "[...] uma atividade complexa, plural, que se desenvolve em várias direções." tendo como foco a "interação autor- textoleitor", altamente complexa de produção de sentidos [...]" (KOCH; ELIAS, 2009, p. 11).

Neste texto, comentamos sobre: a leitura na sala de aula de EJA e as medições didáticas utilizadas por uma professora de EJA; considerando aspectos referentes à: I. Leitura na sala de aula da EJA - mediação do professor, II. Percursos da Pesquisa: contextos, sujeitos e procedimentos metodológicos, III. Vivências/experiências das mulheres da EJA do/no observatório alagoano de leitura na EJA e apresentamos as mediações didáticas vivenciadas por uma professora, a partir das sessões de estudo e de reflexão ${ }^{3}$, ambos vivenciadas no processo da pesquisa formação.

Para tanto, utilizamos dados empíricos que ofereceram possibilidades de análises e contributos para o ensino de Leitura na EJA, possíveis de gerar mudanças na prática pedagógica e nas aprendizagens dos alunos, inspirando-nos em Freire (1996, p. 32), quando diz: "Pesquiso para conhecer o que ainda não conheço e 


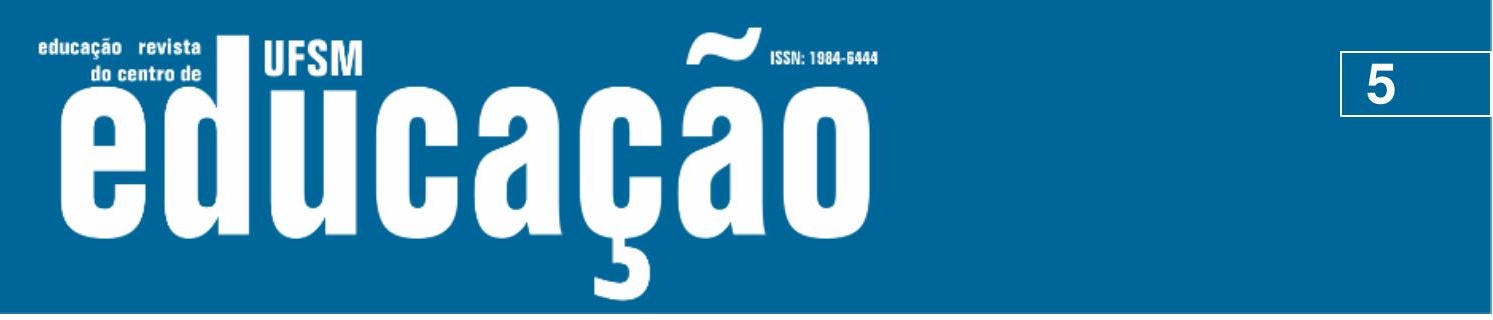

ISSN: 1984-6444 | http://dx.doi.org/10.5902/1984644460844

Assim, a leitura passa a ser compreendida como um processo ativo de construção de sentidos, necessitando da interação entre leitor e autor, tendo como veículo o texto. Segundo Koch \& Elias (2009, p. 12):

[...] na concepção interacional (dialógica) da língua, os sujeitos são vistos como atores/construtores sociais, sujeitos ativos que - dialogicamente - se constroem e são construídos no texto, considerando o próprio lugar da interação e da constituição dos interlocutores.

Os estudos interacionistas de leitura reconhecem que as dificuldades encontradas em relação à compreensão de um texto estão relacionadas não só às dificuldades de decodificar as unidades linguísticas por parte dos leitores, mas, sobretudo, com a falta de conhecimentos prévios dos sujeitos no ato de ler.

Essa abordagem enfatiza que os autores deixam as marcas de intencionalidade nos textos produzidos, por meio das pistas linguísticas, cabendo ao leitor recuperar a intenção do autor, reconstruindo os sentidos a partir de seus conhecimentos de mundo. Dessa forma, o leitor deixa de ser um "depósito" de informações contidas no texto e passa a ser um coautor do material que está lendo.

Podemos afirmar que a compreensão do texto, neste processo, depende principalmente do propósito do leitor. Os professores que adotam essa concepção de leitura acreditam que existem diferentes formas de leitura para diversas situações da vida, nesse sentido, conforme nos lembra Solé (1998): existe a leitura para deleite (gêneros literários, anedotas, crônicas, etc); a leitura para trabalho (gêneros profissionais - relatórios, manuais de instruções, etc.) a leitura para estudo (gêneros didáticos - exposições, dissertações, ensaios, etc.); a leitura para autoajuda (parábolas, fábulas, pensamentos, etc.) e algumas outras funções sociais que a leitura assume na sociedade. Sendo assim, todos os gêneros textuais devem ser prestigiados nas salas de aula da EJA.

Para Bakhtin (2006, p. 285):

Quanto melhor dominamos os gêneros tanto mais livremente os empregamos, tanto mais plena e nitidamente descobrimos neles a nossa individualidade (onde isso é possível e necessário), refletimos de modo mais flexível e sutil a situação singular da comunicação; em suma, realizamos de modo mais acabado o nosso livre projeto de discursos. 


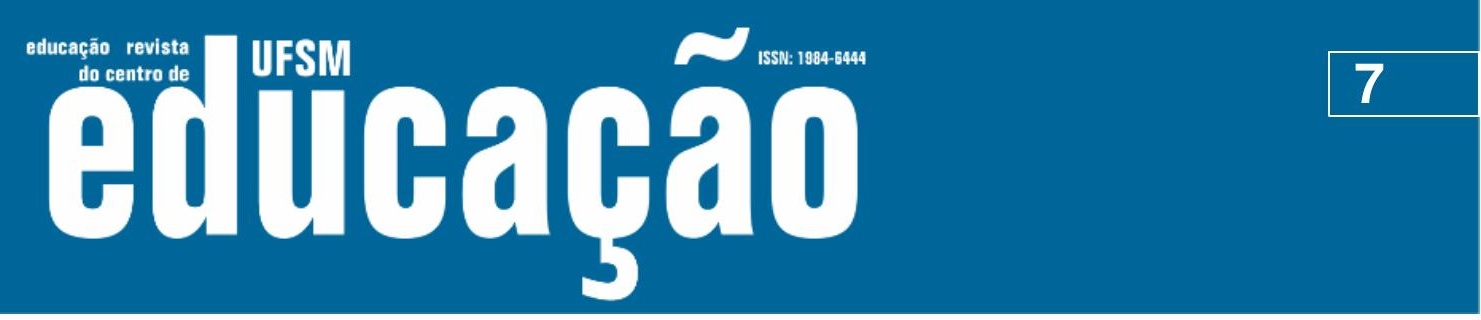

ISSN: 1984-6444 | http://dx.doi.org/10.5902/1984644460844

aprendizagem produzem e ampliam seus conhecimentos. Partindo desse pressuposto, entende-se que a mediação didática nas aulas de leitura da EJA deve permitir a formação de leitores críticos, considerando que "a reflexão didática parte do compromisso com a transformação social, com a busca de práticas pedagógicas que tornem o ensino de fato eficiente [...]." (CANDAU, 1993, p. 10). Nesta concepção ao se implementar práticas de leitura na EJA, o educador deve estabelecer relações dialógicas entre o sujeito/leitor e o texto lido.

Isso porque a constituição dialógica do sujeito sustenta-se na enunciação, entendida como um processo social em que o "eu" institui-se mediado no outro e como o outro, sendo pela inter-relação entre dialogismo e alteridade que emerge o diálogo, tendo em vista que o homem nunca encontrará sua plenitude apenas em si mesmo, (BAKHTIN, 2006, p. 180).

Durante a trajetória de nossa pesquisa compreendemos que os fundamentos político-epistemológicos e reflexões nos permitiram avançar para além da dicotomização e da hierarquização entre os diferentes conhecimentos e didáticas desenvolvidas nas salas de aula da EJA. Entendendo, portanto, que os conhecimentos construídos nas salas de aula de leitura observadas se enredaram aos processos de reflexão em torno da emancipação social e da possível contribuição das escolas a esse processo.

Ao focar nossa atenção nas mediações didáticas nas aula de leitura na EJA, compreendemos que os sujeitos da pesquisa, estudantes jovens, adultos e idosos, junto com as professoras trouxeram saberes de suas vidas para a escola, e esses saberes se entrelaçaram nas salas de aula, sobretudo nas aulas de leitura, construindo processos de mútuos de conhecimentos. Numa perspectiva dialógica contínua, permitindo desvelar intenções e compromissos éticos, explicitando o sentido e a coerência das ações, como sempre nos ensinou Freire (1975).

Diante desses pressupostos, reconhecemos que as salas de aula da EJA são espaços de diálogos que ampliam os conhecimentos dos estudantes. $E$ a dialogicidade poderá permitir a construção de didáticas democráticas e emancipatórias nas salas de aula. No âmbito educacional há que se ressaltar que dialogar não pode ser "catequizar", mas socializar para uma reflexão-ação. Dialogar é 


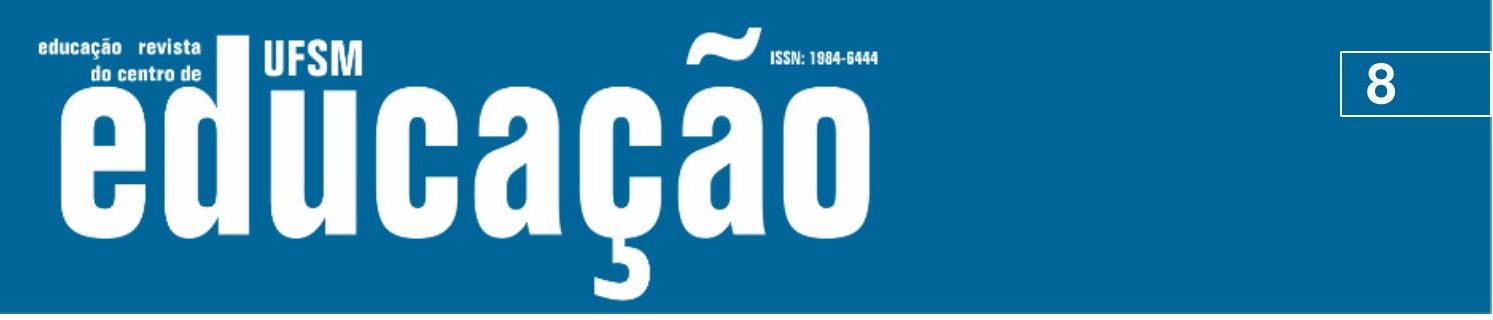

ISSN: 1984-6444 | http://dx.doi.org/10.5902/1984644460844

problematizar o fazer pedagógico e suas consequências, é suscitar exigências para a mudança. Não se trata de apresentar respostas prontas, mas questionar as intenções e contradições do constituído, processar a reconstrução.

Nesse sentido, o diálogo torna-se a concretização do próprio exercício para a liberdade, uma vez que, segundo Freire (1992, p. 92),

[...] a existência, porque humana, não pode ser muda, silenciosa, nem tampouco pode nutrir-se de falsas palavras, mas de palavras verdadeiras, com que os homens transformam o mundo. Existir, humanamente, é pronunciar o mundo, é modificá-lo. O mundo pronunciado, por sua vez, se volta problematizado aos sujeitos pronunciantes, a exigir deles novo pronunciar.

Ressaltamos, portanto, a importância do educador enquanto mediador nas aulas de leitura, reconhecendo, que não há nenhum instrumento ou tecnologia que o substitua, sendo assim, sua presença, seu exemplo, sua experiência representam a possibilidade de mediação entre os sujeitos alunos e os conhecimentos sistematizados por intermédio do domínio das habilidades de leitura e escrita que a sociedade vem exigindo.

Nas palavras de Freire, uma Educação como prática da liberdade (1975, p. 150) requer: "[...] que a palavra seja compreendida pelo homem na sua justa significação: como força de transformação do mundo". Transformação social que é mediada pelo diálogo, considerando que "[...] os seres humanos se constroem em diálogos, pois são essencialmente comunicativos". Não há, portanto, educação sem diálogo, e que o momento do diálogo é o momento para transformar a realidade.

Nesse sentido, o educador da EJA comprometido com a emancipação dos estudantes, institui mediações didáticas na área de leitura permeadas pelo diálogo formador e democrático, nesta concepção, ao pensar uma didática da leitura, o educador deve considerar que a mediação didática pressupõe uma epistemologia da prática, que implica em garantir a aprendizagem de todos, como forma de justiça social e curricular (SANTOS, 2010). Tal perspectiva apoia-se na compreensão de que a mediação didática da leitura na EJA deve partir de uma tomada de posição a respeito das concepções de leitura, do lugar do sujeito leitor, dos sentidos atribuídos aos textos e das práticas sociais de uso da leitura no mundo letrado. 


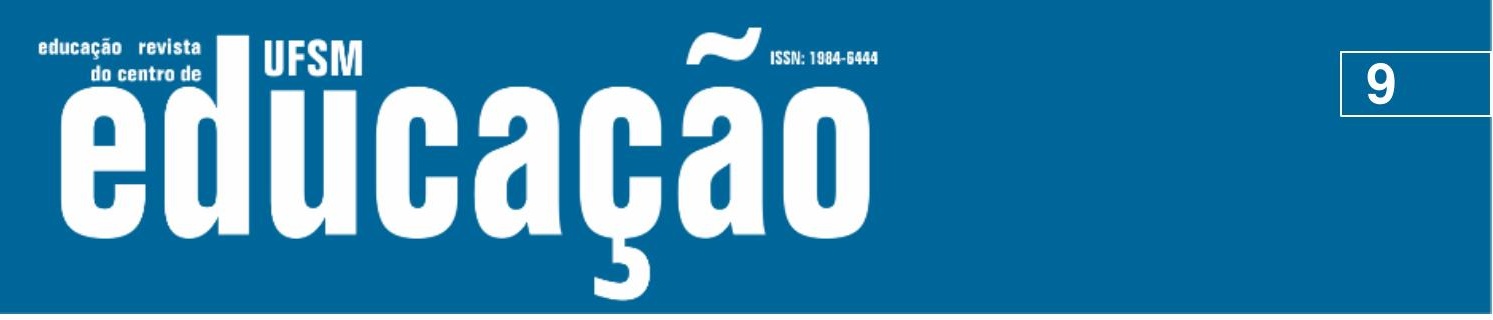

ISSN: 1984-6444 | http://dx.doi.org/10.5902/1984644460844

Considerando as vozes dos sujeitos estudantes e professores, o contexto em que estão inseridos; as comunidades em que vivem, as práticas culturais e sociais com que têm contato em suas comunidades, em suas motivações e expectativas em relação à escola, entre outros. Estamos assumindo que "[...] as escolas públicas como lugares onde, apesar de todas as pressões sofridas, a esperança ainda é um dado de vida. Também queremos, de antemão, deixar registrado nosso otimismo em relação às escolas e aos seus sujeitos" (FERRAÇO, 2001, p. 79).

Dessa maneira, os professores da EJA precisam garantir aos educandos um processo que ultrapasse a visão de apenas ensinar a ler e escrever, ou seja, um ensino de leitura que agregue as duas dimensões do letramento: a individual, que se refere à alfabetização, e a sociocultural que envolve o uso e práticas de leitura e escrita (SOARES, 2003). Uma prática comprometida com indivíduos possuidores de saberes, como afirma Freire (1992, p.36 e 37):

Decência e boniteza de mãos dadas. [...] mulheres e homens, seres históricosociais, nos tornamos capazes de comparar, de valorar, de intervir, de escolher, de decidir, de romper, por tudo isso, nos fizemos seres éticos.

As práticas de leitura e escrita exercidas no contexto escolar não podem ser desvinculadas dos contextos socioculturais reais dos educando, para que os sujeitos da EJA tornem-se leitores experientes e elevem o seu nível de letramento. Leitura assim compreendida enquanto processo de interação de diversos níveis de conhecimento, como o conhecimento linguístico, o textual, o conhecimento de mundo. $\mathrm{E}$, que esses conhecimentos auxiliem na elaboração de uma proposta de leitura que valorize os aprendizes/leitores como sujeitos portadores de conhecimentos, capazes de dialogarem com os autores e negociar significados.

\section{Percursos da Pesquisa: contextos, sujeitos e procedimentos metodológicos}

O corpus que fundamenta nosso diálogo, adveio de observações, que foram gravadas e filmadas, bem como falas dos estudantes, por meio de grupos focais realizados em uma das escolas que dominamos de Rubi - nome fictício - entre as 


\section{ussm

ISSN: 1984-6444 | http://dx.doi.org/10.5902/1984644460844

Quadro 1 - Evento de Aula no. 3 - Música - Terezinha -3ª Fase - Anos Iniciais

Terezinha
O primeiro me chegou
Como quem vem do florista:
Trouxe um bicho de pelúcia,
Trouxe um broche de ametista.
Me contou suas viagens
E as vantagens que ele tinha.
Me mostrou o seu relógio;
Me chamava de rainha.
Me encontrou tão desarmada,
Que tocou meu coração,
Mas não me negava nada
E, assustada, eu disse "não".
O segundo me chegou
Como quem chega do bar:
Trouxe um litro de aguardente
Tão amarga de tragar.
Indagou o meu passado
E cheirou minha comida.
Vasculhou minha gaveta;
Me chamava de perdida.
Me encontrou tão desarmada,
Que arranhou meu coração,
Mas não me entregava nada
E, assustada, eu disse "não".
O terceiro me chegou
Como quem chega do nada:
Ele não me trouxe nada,
Também nada perguntou.
Mal sei como ele se chama,
Mas entendo o que ele quer!
Se deitou na minha cama
E me chama de mulher.
Foi chegando sorrateiro
E antes que eu dissesse não,
Se instalou feito um posseiro
Dentro do meu coração.

Fonte: Internet

Após a escuta da música Terezinha, a professora explorou os elementos do texto e buscou, por meio do diálogo, provocar para que as estudantes fizessem um paralelo entre a letra da música e as suas histórias de vida, chamando a atenção para os significados que se apresentam em forma de poesia. Deu-lhes pistas linguísticas, para que como leitoras recuperassem a intenção do autor, na tentativa de que 


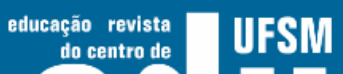 Autuabat}

ISSN: 1984-6444 | http://dx.doi.org/10.5902/1984644460844

assumissem a coautoria do texto, a proporção que as estudantes fossem reconstruindo os sentidos a partir de seus conhecimentos prévios.

Sentindo-se envolvidas as mulheres assumiram o diálogo como protagonistas, conforme veremos:

Fragmento1

PA - Oi gente vocês ouviram a música? Já conheciam?

E1 - Eu conhecia professora, ela é um pouco antiga;

E2 - Eu também já conhecia, é boa né professora?

$P A$ - Eu acho muito boa dona $M$, e aí a música fala de quê? Afinal quem era Terezinha? Que mulher é essa? Como ela vivia/vive? O que acontecia com ela? Digam aí mulheres? O que vocês acham, mesmo as que não conheciam;

E1 - Professora eu estou entendendo que a Terezinha, teve muitos namorados, ela era Namoradeira (risos); igual a mim, (risos);

E2 - Verdade $L$ eu acho que ela teve muitos namorados, ganhou presentes desses homens, eu mesma entendo que a música diz isso: Trouxe um bicho de pelúcia, trouxe um broche de ametista, acho que ela ficou feliz;.

PA - Sim, mas ela tem alegria? E o que mais J, você que é a mais nova da turma o que acha?

E3 - Eu fiquei pensando que ela sofreu muito na vida, com esses homens; PA - J por que você acha que ela sofreu? Onde aparece na música que ele sofreu?

E3 - Eu ouvi, e está escrito aqui na música, diz assim: Ele vasculhou minha gaveta; me chamava de perdida; Professora essa história eu conheço bem;

$P A$ - Entendo J você mesmo nova tem uma vida sofrida, você contou aqui

E4 - É professora nós já conversamos sobre violência doméstica;

Nos diálogos constatamos que as trabalhadoras-estudantes estavam muito envolvidas com a temática discutida em sala, sentindo-se à vontade para colocar seus sentimentos, como por exemplo, quando E1 - afirma: Professora eu estou entendendo que a Terezinha, teve muitos namorados, igual a mim, ou ainda quando E3 diz: [...] Ele vasculhou minha gaveta; me chamava de perdida; Professora essa história eu conheço bem. 


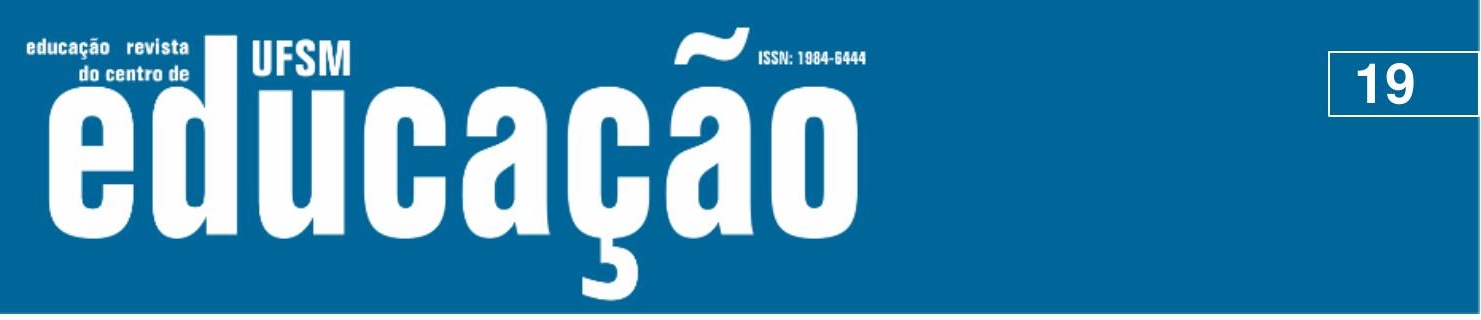

ISSN: 1984-6444 | http://dx.doi.org/10.5902/1984644460844

O diálogo entre a letra da música e a identidade das estudantes fez com que que submergissem suas memórias, suas histórias de vida, desencadeando uma interação autor-leitoras. Interação essa, que entrelaçaram as suas vidas ao conteúdo poético da música.

Concordando com Freire (1979), percebe-se que as estudantes, nesse momento, estavam vivenciando uma educação humanizante, circunscrita às sociedades e a mulheres concretas, indo na contramão de uma: "[...]:educação para a “domesticação', para a alienação e como educação para a liberdade. 'Educação' para o homem-objeto ou indivíduo para o homem sujeito" (FREIRE, 1979, p. 36).

O diálogo, nessa aula, foi revelando que o conhecimento que foi sendo tecido, superando a previsibilidade, tomando como referência o conhecimento trazido por meio das redes de conhecimentos das estudantes. Como podemos perceber, a mediação didática da professora convida os estudantes a refletirem e avançarem no diálogo, embora algumas se mantiveram em silêncio, o que pode ser traduzida como uma outra forma de linguagem; outras sentiram-se à vontade para trazerem histórias, suas realidades e as vivências tão próximas do eu lírico do poema.

As narrativas das estudantes nos permitiu compreender e enxerga-las como pessoas, com suas mais variadas histórias, e perceber suas especificidades para além da escola e da sala de aula.

Fragmento 2

E4 - Quando a senhora tava lendo eu fiquei também pensando que parece com minha vida, por que eu tive um companheiro assim, mas hoje tenho um homem bom. "Ele não me perguntou nada, mas se instalou no meu coração[...]", achei bonita essa parte da música. Hoje posso estudar, e viver a minha vida.

E5 - Eu também dona $R$ - entrou no diálogo, uma aluna que tinha ficado em silêncio -, pensei na minha vida, tive muitos homens no interior [referindo-se à cidade onde residiu], agora que estou mais idosa deixei essa vida para lá, homem dá muito trabalho.

O diálogo acima registrado entre a professora e as estudantes foi construído, mais uma vez, relacionando as identidades dos estudantes com a música, de modo próprio às regras que lhes são dadas para consumo, como refere E4 - Quando a 


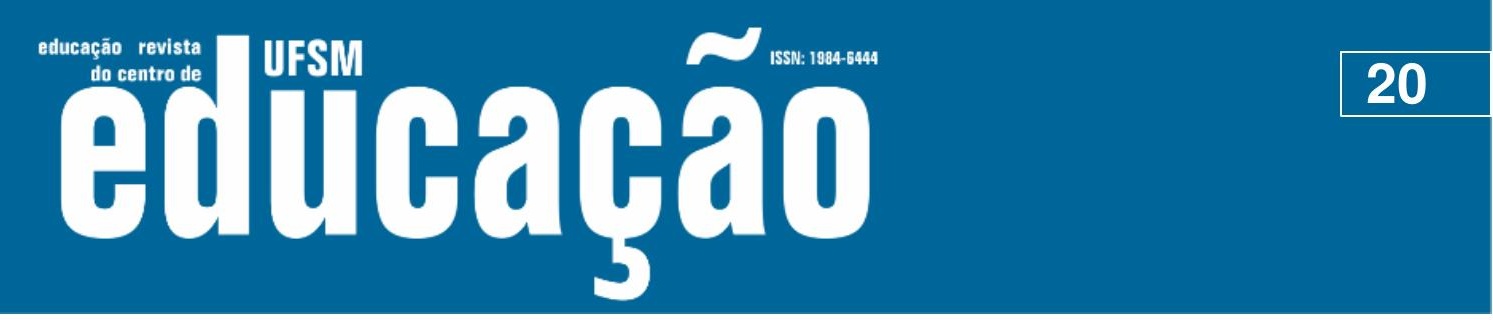

ISSN: 1984-6444 | http://dx.doi.org/10.5902/1984644460844

senhora tava lendo eu fiquei aqui pensando, parece com minha vida, e E5 - Eu também dona $B$, pensei na minha vida eu também fiquei pensando quando eu ainda morava no interior, eu sofri muito, primeiro com meu pai depois com meu casamento.

Como podemos constatar neste diálogo, as trabalhadoras-estudantes mesmo tendo um currículo que lhes é imposto rompem, na sala de aula, com essa prescrição curricular, trazendo suas histórias de vidas e realidades para a aula de leitura.

A leitura em forma de música possibilitou construir uma educação dialógica, em que as estudantes da EJA tiveram seus saberes reconhecidos, suas histórias, suas verdades e realidades. Educação compreendida como uma atividade extremamente importante no processo formativo do indivíduo, indo muito além de apenas decodificar letras e palavras.

Nesse aspecto, os diálogos nesta aula, especificando o discurso das estudantes, mostram-nos que, mesmo diante de suas situações de subalternidade em relação à vida, situações socioeconômicas, ou como elas mesmas afirmam "mesmo com todas as dificuldades da vida",[...] "Hoje posso estudar, e viver a minha vida", essas mulheres insistem em permanecer na escola. E nessa caminhada, no cotidiano das escolas da EJA, ao nos envolver mais com as estudantes fomos percebendo que a cada dia na sala de aula, resistem, permanecem burlando e nos mostraram que têm condições de aprender e superar dificuldades enfrentadas no contexto interno e externo à instituição escolar.

Nessa aula de leitura, especificamente, ficam explícitos os modos específicos e singulares como a professora, com sua mediação libertadora, deu-lhes outros contornos, contrariando, assim, a perspectiva da educação bancária. Percebemos, também, que a professora assume uma prática comprometida com a ética, à medida que reconheceu:

[...] nos educandos um processo de saber mais, os sujeitos, com ele, deste processo e não pacientes acomodados; segundo, reconhecer que 0 conhecimento não é dado aí, algo imobilizado, concluído, terminado, a ser transferido por quem o adquiriu e quem não o adquiriu (FREIRE, 1992, p. 29).

Consideramos que essa aula, em específico, constituiu-se como possibilidade emancipatória na/da EJA, nesse sentido, os conhecimentos das mulheres da EJA que 


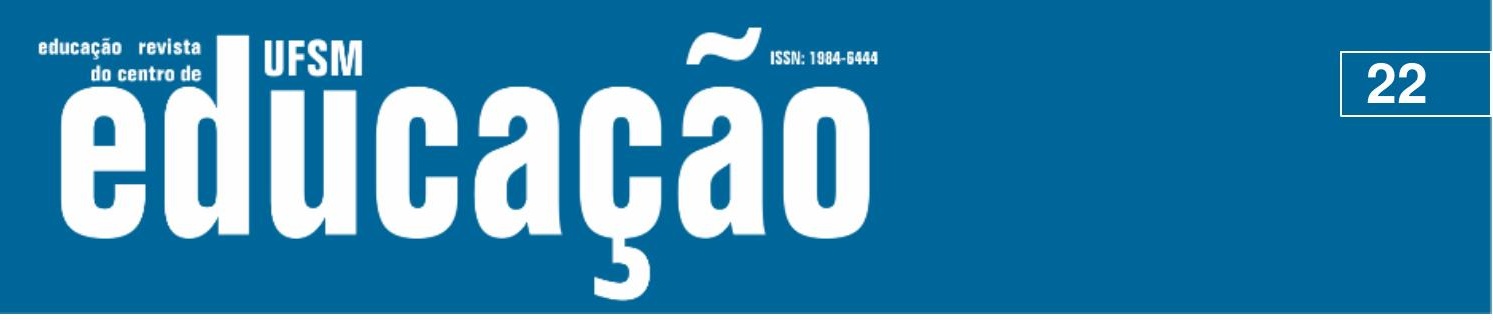

ISSN: 1984-6444 | http://dx.doi.org/10.5902/1984644460844

Isso contribuiu, não para encontrar "culpados", mas, para que todos os envolvidos/as na pesquisa se reconhecessem como produtores/as de conhecimentos.

Nesse processo, a professora em foco a partir das mediações didáticas em sala de aula, por meio da música e utilizando uma concepção de língua como interação, que assume o objetivo e o subjetivo, como elementos de interpretação, proporcionou aos estudantes e a si a possibilidade de produção de conhecimentos e de leituras significativas da realidade, rompendo com a dicotomia existente entre os saberes escolares e os saberes docentes e discentes.

Observamos ainda a ausência de controle regulador por parte da professora, que permitiu às estudantes tecerem conhecimentos de forma dinâmica e múltipla, que não foram medidos nem controlados, seguiram a força das experiências pessoais no entrecruzamento de valores, significações.

Nessa perspectiva, as estudantes e a professora praticaram diferentes modos de experimentar/problematizar a leitura que não foram centrados em verdades absolutas e, sim, na horizontalidade em que os conhecimentos das estudantes foram reconhecidos e valorizados, não existindo uma hierarquização de saberes. A inserção crítica do real na sala de aula proporcionou aos envolvidos a superação possível das limitações que a vida lhes impõe.

\section{Referências}

ALVES, Nilda e GARCIA, Regina Leite (Org.). A invenção da escola a cada dia. Rio de Janeiro: DP\&A, 2002.

ALVES, Nilda e GARCIA, Regina Leite (Org.). Decifrando o pergaminho - o cotidiano das escolas nas lógicas das redes cotidianas. In: OLIVEIRA, Inês Barbosa; ALVES, Nilda. (Orgs.). Pesquisa nos/dos/com os cotidianos das escolas - sobre redes e saberes. Petrópolis: DP et Alii, 2012.

ALVES, Nilda e GARCIA, Regina Leite (Org.). Nós somos o que contamos: a narrativa de si como prática de formação. In: SOUZA, Elizeu Clementino de; MIGNOT, Ana Chrystina Venancio. Histórias de vida e formação de professores. Rio de Janeiro: FAPERJ, 2008. 


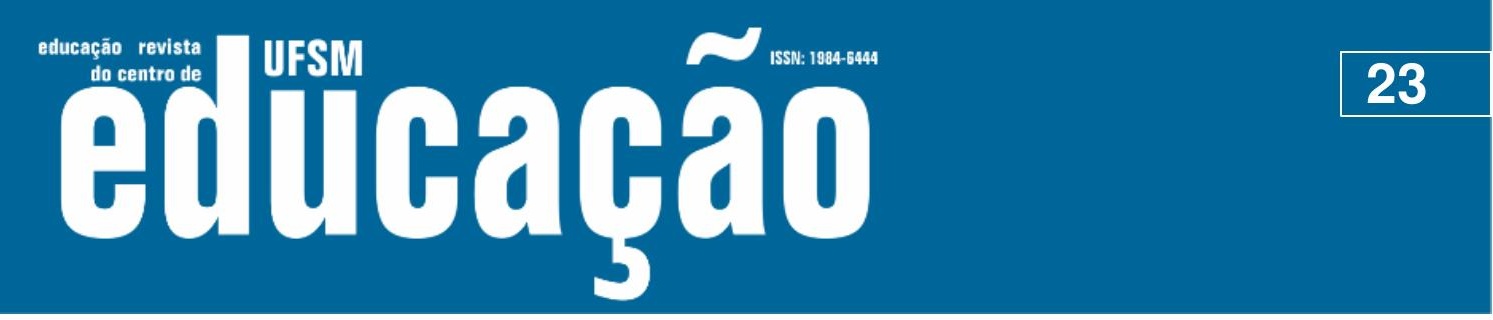

ISSN: 1984-6444 | http://dx.doi.org/10.5902/1984644460844

ALVES, Nilda e GARCIA, Regina Leite (Org.). Redes educativas "dentrofora" das escolas: exemplificadas pela formação de professores. In: SANTOS, Lucíola (Org.). Convergências e tensões no campo da formação e do trabalho docente: currículo, ensino de educação física, ensino da geografia, ensino da história, escola, família e comunidade. Belo Horizonte: Autêntica, 2010.

BAKHTIN, Michael. Marxismo e filosofia da linguagem. 12 ed., São Paulo: Hucitec, 2006.

CANDAU, Vera Maria (Org.). Rumo a uma nova didática. Petrópolis: Vozes, 1993.

CANEN, Ana; XAVIER, Giseli Pereli de Moura. Formação continuada de professores para a diversidade cultural. Revista Brasileira de Educação v. 16 n. 48 set.-dez. 2011, p. 642.

CAVALCANTE, Valéria Campos. Leitura na educação de jovens e adultos: um estudo de eventos e práticas de letramento em salas de aula do $1^{\circ}$ - segmento. 2013. Dissertação (Mestrado em Educação). Universidade Federal de Alagoas, Maceió, 2013.

DE CERTEAU, Michel. A invenção do cotidiano. 15 ed. Petrópolis: Vozes, 1994.

FERRAÇO, Carlos Eduardo. Ensaio de uma metodologia efêmera. In: OLIVEIRA, Inês. Barbosa. de; ALVES, Nilda. (Orgs.). Pesquisa no/do cotidiano das escolas. Rio de Janeiro: DP\&A, 2001.

FREIRE, Paulo. Conscientização: teoria e prática da liberdade. São Paulo: Moraes, 1975.

FREIRE, Paulo. Educação como prática da liberdade. 9. ed. Rio de Janeiro: Paz e Terra, 1979.

FREIRE, Paulo. Pedagogia da autonomia. Rio de Janeiro: Paz e Terra, 1992.

FREIRE, Paulo. Pedagogia do oprimido. 3. ed. Rio de Janeiro: Paz e Terra, 1996.

IBIAPINA, Ivana Maria Lopes de Melo. Pesquisa colaborativa: investigação, formação e produção de conhecimento. Brasília: Líber Livro Editora, 2008.

$\mathrm{KOCH}$, Ingdore V.; ELIAS, Maria V. Ler e compreender os sentidos do texto. São Paulo: Contexto, 2009.

LOURO, Guacira Lopes. Gênero, sexualidade e educação. Uma perspectiva pósestruturalista. 6ª ed. - Petrópolis: Vozes, 1997.

LOURO, Guacira Lopes. Teoria queer - uma política pós-identitária para a educação. Revista Estudos feministas. p. 541-553. 2/2001. 


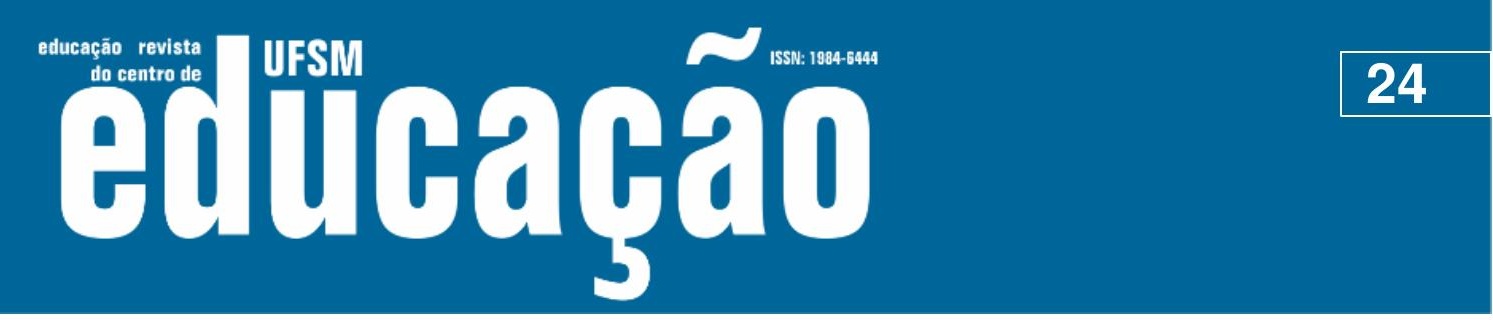

ISSN: 1984-6444 | http://dx.doi.org/10.5902/1984644460844

MORIN, Edgar. Os sete saberes necessários à educação do futuro. Tradução de Catarina Eleonora F. da Silva e Jeanne Sawaya; revisão técnica de Edgard de Assis Carvalho. - 8. ed. - São Paulo: Cortez; Brasília, DF: UNESCO, 2003.

MARCUSCHI, Luiz Antônio. Produção textual - análise de gêneros e compreensão. São Paulo: Parábola, 2008.

OLIVEIRA, Inês Barbosa. Currículos praticados: entre a regulação e a emancipação. Rio de Janeiro: DP\&Alli, 2008.

OLIVEIRA, Inês Barbosa. O currículo como criação cotidiana. Rio de Janeiro: DP\&Alli, 2012.

UNESCO. Declaração de Hamburgo sobre Educação de Adultos. Hamburgo: V Conferência Internacional sobre Educação de Adultos- (V CONFINTEA), 1997. Disponível em: http://www.cidadedoconhecimento.org.br Acesso em: 03 de mar. 2020.

UNESCO. Conferência Internacional de Educação de Adultos (V: 1997, Hamburgo, Alemanha). Declaração de Hamburgo, Agenda para o Futuro. Brasília: SESI/UNESCO, 1999.

UNESCO. Conferência Internacional de Educação de Adultos (VI: 2009, Belém, Brasil). Marco de Ação de Belém. Brasília: UNESCO/MEC, abril de 2010.

SANTOS, Boaventura de Sousa. Introdução a uma ciência pós-moderna. Rio de Janeiro: Graal, 1989.

SANTOS, Boaventura de Sousa. A crítica da razão indolente: contra o desperdício da experiência. 4르ed. São Paulo: Editora Cortez, 2002.

SANTOS, Boaventura de Sousa. Para uma sociologia das ausências e uma sociologia das emergências, Revista Crítica de Ciências Sociais, (2002a), nํ63, p. 237-28.

SANTOS, Boaventura de Sousa. (Org.). Conhecimento prudente para uma vida decente: um discurso sobre as ciências revisitado. São Paulo: Cortez, 2004. p. 77782.

SMOLKA, Ana Luiza B. Múltiplas vozes em sala de aula: aspecto da construção coletiva do conhecimento na escola. Revista de Trabalhos de Linguística Aplicada, Campinas: UNICAMP, 1991, n. 18, p. 15-28, jul./dez.

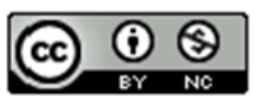

This work is licensed under a Creative Commons Attribution-NonCommercial 4.0 International (CC BY-NC 4.0) 


\title{
N

ISSN: 1984-6444 | http://dx.doi.org/10.5902/1984644460844

\section{Notas}

\begin{abstract}
${ }^{1}$ O Grupo de Trabalho do Observatório envolveu: 11 professoras, sendo 04 objetos de estudo e bolsistas da Capes, com atuação em turmas dos anos iniciais do Ensino Fundamental de EJA; 04 bolsistas Capes, 03 bolsistas do Programa Institucional de Bolsas de Iniciação Científica (Pibic), todos estudantes, predomindantemente, do curso de Pedagogia e um bolsista Capes com formação em jornalismo, para o apoio logístico as ações de filmagens, edição e elaboração do videodocumentário; 03 pesquisadoras da Ufal, em nível de coordenação da pesquisa, que atuaram com executores e fizeram uma coordenação colegiada e 03 pesquisadoras colaboradoras, sendo duas, também, professoras da Ufal e uma técnica da Secretária Executiva de Educação do Estado de Alagoas, que em 2014 inseriu-se com professora no quadro docente da Ufal.
\end{abstract}

${ }^{2}$ Entende-se que o caráter formativo de uma pesquisa formação não se reduz à eleição de temas educacionais aleatórios, mas permite a inserção de um modo de fomentar uma cultura de formação na escola a partir dos desafios postos e impostos pela cultural escolar.

${ }^{3}$ Sessões de estudos e reflexões - eram momentos de encontros nos quais se realizam estudos de textos e pesquisas sobre leitura, sujeitos da EJA, teóricos. Esses encontros aconteciam semanalmente nas escolas participantes da pesquisa. Nestes momentos havia um processo de formação com o grupo da escola, estavam presentes professoras, coordenadoras e gestores que atuavam na EJA.

${ }^{4}$ No município de Maceió o Ensino Fundamental de EJA é composto de seis fases, sendo a terceira fase correspondente a última dos anos iniciais.

${ }^{5}$ SILVA, Rosa Helena D. Da. Escolas em movimento: trajetória de uma política indígena da educação. Cadernos de Pesquisa. São Paulo: Fundação Carlos Chagas, n. 111, dez. 2000.

${ }^{6}$ HALL, Stuart. A identidade cultural na pós-modernidade. Rio de Janeiro: DP\&A, 1999.

${ }^{7}$ Optamos por apresentar ao longo do trabalho sintagmas (nominais ou verbais) juntos, com o propósito de deixarmos claro a indissociabilidade semântica que existe entre eles. 